\title{
Screening of Metal Chloride Anion-based lonic Liquids for Direct Conversion of Hydrogen Sulfide by COSMO-RS
}

\author{
Muhammad Syahir Aminuddin ${ }^{1}$, Zakaria Man ${ }^{1}$, Mohamad Azmi Bustam @ Khalil ${ }^{1}$ and Bawadi Abdullah"," \\ ${ }^{1}$ Universiti Teknologi PETRONAS, Chemical Engineering Department, 32610 Bandar Seri Iskandar, Perak, Malaysia
}

\begin{abstract}
In order to identify the best possible reaction media for performing $\mathrm{H}_{2} \mathrm{~S}$ conversion, a total number of 300 different ILs from a combination of 20 cations and 15 anions were screened via COSMO-RS model simulations. By COSMO-RS method, thermodynamic and physicochemical properties of 300 ILs such as Henry's law constants, activity coefficient, selectivity, capacity and performance index are obtained and analyzed. Thus, by comparing the performance of ILs via COSMO-RS, a series of TSILs containing cation of $\left[\mathrm{P}_{66614}\right]$ with metal chloride anions such as $\mathrm{Fe}, \mathrm{Ga}$ and $\mathrm{Sn}$ were chosen and selected for synthesis based on their performance predicted by COSMO-RS and their economic values. Consequently, the physiochemical properties such as density, viscosity, thermal properties, as well as $\mathrm{H}_{2} \mathrm{~S}$ absorptive oxidation performances in those TSILs will be systematically investigated.
\end{abstract}

Keywords-Task Specific Ionic Liquids; Conversion of $\mathrm{H}_{2} \mathrm{~S} ; \mathrm{H}_{2} \mathrm{~S}$; Sour Natural Gas

\section{Introduction}

Hydrogen sulfide $\left(\mathrm{H}_{2} \mathrm{~S}\right)$ is a poisonous gas commonly found in natural gas fields, crude oil, biogas and syngas [1]. $\mathrm{H}_{2} \mathrm{~S}$ is highly toxic and its hazardous effects towards living organisms could be seen as low as at $10 \mathrm{ppm}$ of concentration and could cause death after exceeding 500 ppm [2]. It is also very corrosive to carbon steel [3], which is usually used in the pipelines and production such as storage tanks in oil and gas industry [4]. Therefore, the removal of $\mathrm{H}_{2} \mathrm{~S}$ is very important for safety and economic purposes.

Industrially, there are different methods involved in natural gas desulphurization processes such as absorption, adsorption and conversion of $\mathrm{H}_{2} \mathrm{~S}$ into elemental sulfur. Among these processes, LO-CAT and Claus process possess remarkable advantages of converting $\mathrm{H}_{2} \mathrm{~S}$ to elemental sulfur, $\left(\mathrm{S}_{8}\right)$ at higher efficiencies [5]. However, these commercial technologies are energy intensive processes and suffer with degradation and catalyst deactivation, resulting in lower sulfur production output and high cost of conversion [6].

Ionic liquids (ILs) are salts with melting point below $100^{\circ} \mathrm{C}$. It is a new class of green solvents with a potential use in natural gas sweetening processes [7]. ILs are widely known as "designer solvents" due to its tunable physicochemical properties such as density, viscosity, hydrophobicity, polarity and etc. by interchanging the cation and anion of the ILs [8]. These unique properties can be harnessed for $\mathrm{H}_{2} \mathrm{~S}$ conversion processes.

In recent years, a lot of studies have been carried out focusing on conversion of $\mathrm{H}_{2} \mathrm{~S}$ into elemental sulfur by using ILs [9]. Many studies have reported the potential use and candidacies of conventional room temperature ILs (RTILs) for $\mathrm{H}_{2} \mathrm{~S}$ conversion experimentally $[10,11]$. However, it is found out that the solubility and capacity of $\mathrm{H}_{2} \mathrm{~S}$ in these ILs are still low at low pressure and thus, unable to perform their tasks efficiently [12-16]. Therefore, a new kind of ILs, Task Specific ILs (TSILs) such as metal chloride anion based ILs has been proposed in this research for conversion of $\mathrm{H}_{2} \mathrm{~S}[17,18]$. By considering the conversion efficiency achievable with such TSILs, it is expected that such TSILs can potentially promote faster conversion of $\mathrm{H}_{2} \mathrm{~S}$ to $\mathrm{S}_{8}[19,20]$.

However due to limitless combinations possibility between cations and metal chloride anions that are available for the synthesis, the evaluation of the most appropriate metal chloride anion based ILs for oxidative absorption or direct conversion of $\mathrm{H}_{2} \mathrm{~S}$ is very expensive and time consuming if carried out experimentally [21,22], and also impossible to be performed. The opportunities to identify and select new ILs will also be wasted [23]. Hence, to select the best ILs with desired properties efficiently, all possible ILs must be screened systematically and thoroughly by changing the respective cations and anions [24].

The potential ILs were screened by using a quantum chemical based, Conductor-like Screening Model for Real Solvents (COSMO-RS) developed by Klamt et al. [25] for the prediction of liquids thermodynamic properties. The main advantage of COSMO-RS for screening ILs is its ability to predict the properties of the mixtures' components without any prior experimental data needed. Specifically, COSMO-RS is used for predicting solvent selectivity and capacity for $\mathrm{H}_{2} \mathrm{~S}$ in ILs at infinite dilution.

\footnotetext{
*Corresponding author: bawadi_abdullah@utp.edu.my; bawadi73@gmail.com
} 
Based on the selectivity and capacity of $\mathrm{H}_{2} \mathrm{~S}$, the performance of ILs in conversion of $\mathrm{H}_{2} \mathrm{~S}$ can be predicted. There were a few previous studies that reports the screening of ILs for desulfurization of $\mathrm{H}_{2} \mathrm{~S}$ [26-30]. The novelty of this study compared to previous studies is this is the first study that emphasize the screening of metal chloride anions based ILs for direct conversion of $\mathrm{H}_{2} \mathrm{~S}$.

\section{Computational methods}

\subsection{COSMO-RS method}

COSMO-RS is used to predict the thermophysical properties in various type of systems. For example in COSMO calculations, ILs are treated as equimolar mixtures consisting of cations and anions [31]. Therefore by using the TURBOMOLE program package [32], various COSMO files were generated for cations and anions using Becke and Perdew (BP) functional [33] with triple zeta valence polarized (TZVP) basis set [34].

\subsection{Property calculation}

The mixture properties for ILs and $\mathrm{H}_{2} \mathrm{~S}$ are set at room temperature and pressure condition. All the COSMO-RS calculations were implemented with the COSMOtherm program [35], which offers an efficient performance of the COSMO-RS method.

\subsubsection{Henry's law constant}

Henry's law states that at a constant temperature, the solubility of a gas in a liquid is directly proportional to the pressure of the gas. Thus, the solubility of a gas at a unit pressure is equal to Henry's constant [36]. Solubility of $\mathrm{H}_{2} \mathrm{~S}$ for 300 ILs can be predicted directly by using the Henry's law constants values for all obtained from COSMO-RS screening. A lower prediction value of Henry's law constant indicates a higher solubility of $\mathrm{H}_{2} \mathrm{~S}$ in ILs.

\subsubsection{Activity coefficient}

Activity coefficient is the ratio of the chemical activity of any substance to its molar concentration. In this particular research, COSMO-RS has been used intensively to predict the activity coefficient at infinite dilution, $\left(\gamma^{\infty}\right)$ values of $\mathrm{H}_{2} \mathrm{~S}$ in various ILs from combinations of multiple cations and anions. $\gamma^{\infty}$ values are important because it quantifies the differences of the strength between the molecular interactions and thus providing clear insights of the complex ILs-based system at the molecular levels. Besides, the measurement of $\gamma^{\infty}$ data are cheaper and more convenient compared to liquid-liquid equilibria (LLE) and vapour-liquid equilibria (VLE) diagrams [37].

Activity coefficient at infinite dilution prediction by COSMO-RS is significant for evaluating the selectivity and capacity of ILs for oxidative absorption of $\mathrm{H}_{2} \mathrm{~S}$ [38]. Selectivity and capacity are two crucial parameters in determining the extractive strength of the solvent. The predictions of activity coefficient by COSMO-RS only require molecular structures of the chemical species involved in the reaction. In order to predict the activity coefficient at infinite dilution, $\left(\gamma^{\infty}\right)$ by COSMO-RS, the ILs are treated to have equimolar concentrations of cations and anions. The activity coefficient $(\gamma)$ of $\mathrm{H}_{2} \mathrm{~S}$ at infinite dilution in $300 \mathrm{ILs}$ at $298.15 \mathrm{~K}$ is calculated from the COSMO-RS prediction results.

\subsubsection{Selectivity}

Selectivity of $\mathrm{H}_{2} \mathrm{~S}$ in ILs that acts as a reaction media or catalyst is the ability of the ILs to direct a reaction which favors $\mathrm{H}_{2} \mathrm{~S}$ over $\mathrm{O}_{2}$ to yield a particular product which is elemental sulfur. Selectivity is calculated as the ratio of composition of $\mathrm{O}_{2}$ and $\mathrm{H}_{2} \mathrm{~S}$ in IL phase [39] as shown in the following equation (1);

$$
S_{12}^{\infty}=\left(\frac{\gamma_{2}^{\infty}}{\gamma_{1}^{\infty}}\right)^{I L} \text { phase }
$$

where, $\gamma_{2}^{\infty}$ is the activity coefficient of $\mathrm{O}_{2}$ at infinite dilution and $\gamma_{1}^{\infty}$ is the activity coefficient of $\mathrm{H}_{2} \mathrm{~S}$ at infinite dilution. The selectivity for $\mathrm{H}_{2} \mathrm{~S}$ in 300 different ILs from a combination of 20 cations and 15 anions were predicted via COSMO-RS method.

\subsubsection{Capacity}

Capacity of $\mathrm{H}_{2} \mathrm{~S}$ in any specific ILs is the maximum amount of $\mathrm{H}_{2} \mathrm{~S}$ that the specific ILs can contain [40]. Capacity also determines the amount of ILs needed for the removal of $\mathrm{H}_{2} \mathrm{~S}$ by extraction as given in the equation (2) below;

$$
C_{12}^{\infty}=\left(\frac{1}{\gamma_{1}^{\infty}}\right)^{I L} \text { phase }
$$

The capacity for $\mathrm{H}_{2} \mathrm{~S}$ in 300 different ILs from a combination of 20 cations and 15 anions were predicted via COSMO-RS method at $298.15 \mathrm{~K}$.

\subsubsection{Performance Index}

Performance index $(P I)$ measures the performance and effectiveness of any solvent in performing the extraction [41]. Performance index is the product of selectivity and capacity of any solvent at infinite dilution as given in the following equation (3).

$$
P I=S_{12}^{\infty} \times C_{12}^{\infty}
$$

\subsection{Screening of Metal Chlorides Anion-based ILs for $\mathrm{H}_{2} \mathrm{~S}$ Conversion}

In this research, COSMO-RS is used to predict the activity coefficient and selectivity of 300 different types of ILs. In general, ILs can be designed by combining different cations and anions. In this particular research, a total combination of 20 cations and 15 anions of chloride and metal chloride anions are chosen to form a total of 300 metal chloride anion based ILs, which covers almost all reported ILs and their derivatives.

The wide range combination of cations and anions are screened and predicted by COSMO-RS to determine the most efficient reaction media to perform oxidative 
absorption of $\mathrm{H}_{2} \mathrm{~S}$. Their structures and abbreviations are listed in Table 1. The cations used are imidazolium, phosphonium, pyridinium and pyrrolidinium. The anions used are chloride and metal chloride anions such as silver, zinc, cobalt, copper, gold, titanium, iron, chromium, tin, platinum, aluminium, gallium, nickel and indium.

Table 1. List of cations and anions

\begin{tabular}{|c|c|c|c|}
\hline Formal name & Abbreviation & $\begin{array}{c}M W \\
(\mathrm{~g} / \mathrm{mol})\end{array}$ & Structure \\
\hline $\begin{array}{l}\text { 1,3-methyl- } \\
\text { imidazolium }\end{array}$ & {$\left[\mathrm{C}_{1} \operatorname{Im}\right]^{+}$} & 83.11 & \\
\hline $\begin{array}{l}\text { 1-ethyl-3- } \\
\text { methyl- } \\
\text { imidazolium }\end{array}$ & {$[\text { Emim }]^{+}$} & 111.16 & \\
\hline $\begin{array}{l}\text { 1-butyl- } \\
\text { imidazolium }\end{array}$ & {$\left[\mathrm{C}_{4} \mathrm{Im}\right]^{+}$} & 125.19 & \\
\hline $\begin{array}{l}\text { 1-butyl-3- } \\
\text { methyl- } \\
\text { imidazolium }\end{array}$ & {$[\mathrm{Bmim}]^{+}$} & 139.22 & \\
\hline $\begin{array}{l}\text { 1-hexyl-3- } \\
\text { methyl- } \\
\text { imidazolium }\end{array}$ & {$[\mathrm{Hmim}]^{+}$} & 167.27 & \\
\hline $\begin{array}{l}\text { 1-octyl-3- } \\
\text { methyl- } \\
\text { imidazolium }\end{array}$ & {$[\mathrm{Omim}]^{+}$} & 195.32 & \\
\hline $\begin{array}{l}\text { 1-decyl-3- } \\
\text { methyl- } \\
\text { imidazolium }\end{array}$ & {$\left[\mathrm{C}_{10} \mathrm{mim}\right]^{+}$} & 219.27 & \\
\hline $\begin{array}{l}\text { 1-methyl- } \\
\text { pyridinium }\end{array}$ & {$[\mathrm{Mpy}]^{+}$} & 94.13 & \\
\hline $\begin{array}{l}\text { 1-butyl-2- } \\
\text { methyl- } \\
\text { pyridinium }\end{array}$ & {$\left[\mathrm{B}_{2} \mathrm{mpy}\right]^{+}$} & 150.25 & \\
\hline $\begin{array}{l}\text { 1-butyl-3- } \\
\text { methyl- } \\
\text { pyridinium }\end{array}$ & {$\left[\mathrm{B}_{3} \mathrm{mpy}\right]^{+}$} & 150.25 & \\
\hline $\begin{array}{l}\text { 4-methyl- } N \text { - } \\
\text { butylpyridinium }\end{array}$ & {$[4-\mathrm{MBpy}]^{+}$} & 150.25 & \\
\hline $\begin{array}{l}\text { 1-hexyl- } \\
\text { pyridinium }\end{array}$ & {$[\mathrm{Hpy}]^{+}$} & 168.32 & \\
\hline $\begin{array}{l}\text { Tetrabutyl- } \\
\text { phosphonium }\end{array}$ & {$\left[\mathrm{P}\left(\mathrm{C}_{4}\right)_{4}\right]^{+}$} & 259.43 & \\
\hline $\begin{array}{l}\text { Tributyl- } \\
\text { tetradecylphosp } \\
\text { honium }\end{array}$ & {$\left[\mathrm{P}_{44414}\right]^{+}$} & 399.97 & \\
\hline $\begin{array}{l}\text { Trihexyl- } \\
\text { tetradecylphosp } \\
\text { honium }\end{array}$ & {$\left[\mathrm{P}_{66614}\right]^{+}$} & 483.86 & \\
\hline
\end{tabular}

\begin{tabular}{|c|c|c|c|}
\hline Formal name & Abbreviation & $\begin{array}{c}M W \\
(\mathrm{~g} / \mathrm{mol})\end{array}$ & Structure \\
\hline $\begin{array}{l}\text { 1-ethyl-1- } \\
\text { methyl- } \\
\text { pyrrolidinium }\end{array}$ & 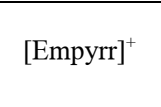 & 122.31 & \\
\hline $\begin{array}{l}\text { 1-butyl-1- } \\
\text { methyl- } \\
\text { pyrrolidinium }\end{array}$ & {$\left[\mathrm{C}_{4} \mathrm{mPyrr}\right]^{+}$} & 144.29 & \\
\hline $\begin{array}{l}\text { 1-butyl-1-ethyl- } \\
\text { pyrrolidinium }\end{array}$ & {$\left[\mathrm{C}_{4} \mathrm{ePyrr}\right]^{+}$} & 156.29 & \\
\hline $\begin{array}{l}\text { 1-hexyl-1- } \\
\text { methyl- } \\
\text { pyrrolidinium }\end{array}$ & {$[\mathrm{Hmpyrr}]^{+}$} & 170.31 & \\
\hline $\begin{array}{l}\text { 1-octyl-1- } \\
\text { methyl- } \\
\text { pyrrolidinium }\end{array}$ & {$[\text { Ompyrr }]^{+}$} & 198.37 & \\
\hline Chloride & {$[\mathrm{Cl}]^{-}$} & 35.45 & \\
\hline $\begin{array}{l}\text { Tetrachloroalu } \\
\text { minate }\end{array}$ & {$\left[\mathrm{AlCl}_{4}\right]^{-}$} & 168.79 & \\
\hline $\begin{array}{l}\text { Dichloroargenta } \\
\text { te }\end{array}$ & {$\left[\mathrm{AgCl}_{2}\right]^{-}$} & 178.78 & \\
\hline $\begin{array}{l}\text { Tetrachlorochro } \\
\text { mate }\end{array}$ & {$\left[\mathrm{CrCl}_{4}\right]^{-}$} & 193.81 & \\
\hline $\begin{array}{l}\text { Tetrachloroferr } \\
\text { ate }\end{array}$ & {$\left[\mathrm{FeCl}_{4}\right]^{-}$} & 197.66 & \\
\hline $\begin{array}{l}\text { Tetrachloronick } \\
\text { elate }\end{array}$ & {$\left[\mathrm{NiCl}_{4}\right]^{2-}$} & 200.51 & \\
\hline $\begin{array}{l}\text { Tetrachlorocob } \\
\text { altate }\end{array}$ & {$\left[\mathrm{CoCl}_{4}\right]^{2-}$} & 200.75 & \\
\hline $\begin{array}{l}\text { Tetrachlorocupr } \\
\text { ate }\end{array}$ & {$\left[\mathrm{CuCl}_{4}\right]^{2-}$} & 205.36 & \\
\hline $\begin{array}{l}\text { Tetrachlorozinc } \\
\text { ate }\end{array}$ & {$\left[\mathrm{ZnCl}_{4}\right]^{2-}$} & 207.22 & \\
\hline $\begin{array}{l}\text { Tetrachlorogall } \\
\text { ate }\end{array}$ & {$\left[\mathrm{GaCl}_{4}\right]^{-}$} & 211.54 & $\mathrm{Cl}$ \\
\hline $\begin{array}{l}\text { Trichlorostanna } \\
\text { te }\end{array}$ & {$\left[\mathrm{SnCl}_{3}\right]^{-}$} & 225.07 & \\
\hline $\begin{array}{l}\text { Tetrachloroindi } \\
\text { um }\end{array}$ & {$\left[\mathrm{InCl}_{4}\right]^{-}$} & 256.56 & \\
\hline $\begin{array}{l}\text { Hexachlorotitan } \\
\text { ate }\end{array}$ & {$\left[\mathrm{TiCl}_{6}\right]^{2-}$} & 260.59 & 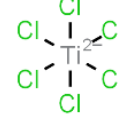 \\
\hline Dichloroaurate & {$\left[\mathrm{AuCl}_{2}\right]^{-}$} & 267.87 & $\mathrm{Cl}$ 、 \\
\hline
\end{tabular}




\begin{tabular}{lccc}
\hline \multicolumn{1}{c}{ Formal name } & Abbreviation & $\begin{array}{c}\boldsymbol{M W} \\
(\mathbf{g} / \mathbf{m o l})\end{array}$ & \multicolumn{1}{c}{ Structure } \\
\cline { 1 - 2 } $\begin{array}{l}\text { Trichloroplatina } \\
\text { te }\end{array}$ & {$\left[\mathrm{PtCl}_{3}\right]^{-}$} & 301.44 & $\mathrm{Cl}_{-\mathrm{Pt}^{-}}-\mathrm{Cl}^{-}$ \\
& & & $\mathrm{Cl}$ \\
\hline
\end{tabular}

\section{Results and discussion}

\subsection{Electronegativity of the metals in the metal chloride anions based ILs}

Electronegativity refers to the atomic ability to attract the electrons from the atoms bonded to it .The electronegativity of the anions play a major role in affecting the selectivity and capacity [42] of the metal chloride anion based ILs for direct conversion of $\mathrm{H}_{2} \mathrm{~S}$ into elemental sulfur. The electronegativity values for all metals used in the screening of metal chloride anion based ILs by COSMO-RS is show in Table 4.3 below [43]. Based on Table 4.3, $\mathrm{Ga}$ is the most electronegative metals followed by $\mathrm{Fe}, \mathrm{Au}, \mathrm{Al}$ and $\mathrm{In}$. Meanwhile, the least electronegative metal is Ti.

Table 1. Table of metals electronegativity in the metal chloride anion based ILs [43]

\begin{tabular}{|c|c|}
\hline Metal chloride anions & Electronegativity \\
\hline$\left[\mathrm{TiCl}_{6}\right]^{2-}$ & 1.225 \\
\hline$\left[\mathrm{CoCl}_{4}\right]^{2-}$ & 1.321 \\
\hline$\left[\mathrm{CrCl}_{4}\right]^{-}$ & 1.322 \\
\hline$\left[\mathrm{AgCl}_{2}\right]^{-}$ & 1.333 \\
\hline$\left[\mathrm{ZnCl}_{4}\right]^{2-}$ & 1.336 \\
\hline$\left[\mathrm{NiCl}_{4}\right]^{2-}$ & 1.367 \\
\hline$\left[\mathrm{CuCl}_{4}\right]^{2-}$ & 1.372 \\
\hline$\left[\mathrm{SnCl}_{3}\right]^{-}$ & 1.427 \\
\hline$\left[\mathrm{PtCl}_{3}\right]^{-}$ & 1.432 \\
\hline$\left[\mathrm{InCl}_{4}\right]^{-}$ & 1.480 \\
\hline$\left[\mathrm{AlCl}_{4}\right]^{-}$ & 1.513 \\
\hline$\left[\mathrm{AuCl}_{2}\right]^{-}$ & 1.550 \\
\hline$\left[\mathrm{FeCl}_{4}\right]^{-}$ & 1.556 \\
\hline$\left[\mathrm{GaCl}_{4}\right]^{-}$ & 1.579 \\
\hline
\end{tabular}

\subsection{Henry's law constants}

The Henry's law constants of $\mathrm{H}_{2} \mathrm{~S}$ in 300 ILs are predicted by COSMO-RS method at $298.15 \mathrm{~K}$, given in a graph of shown in Figure 1. As is well-known, a higher Henry's law constant indicates a lower solubility. A lower prediction value of Henry's law constant indicates a lower solubility of $\mathrm{H}_{2} \mathrm{~S}$ in ILs.

Solubility of $\mathrm{H}_{2} \mathrm{~S}$ is found to be inversely proportional with the electronegativity of the anions. As the electronegativity of the anion decreases, the solubility of $\mathrm{H}_{2} \mathrm{~S}$ in ILs increases. By referring to Table 1, hexachlorotitanate anion, $\left[\mathrm{TiCl}_{6}\right]^{2-}$ based which is the least electronegative compared to the rest of metals used in metal chloride anion based ILs displayed a very low Henry's law constant values, indicating the highest solubility compared to the rest of metal chloride anion based ILs. Meanwhile, metals with higher electronegativity such as $\mathrm{Ga}, \mathrm{Fe}, \mathrm{Au}, \mathrm{Al}$ and $\mathrm{In}$ recorded large Henry's law constant values, indicating a relatively low solubility of $\mathrm{H}_{2} \mathrm{~S}$ in the ILs.

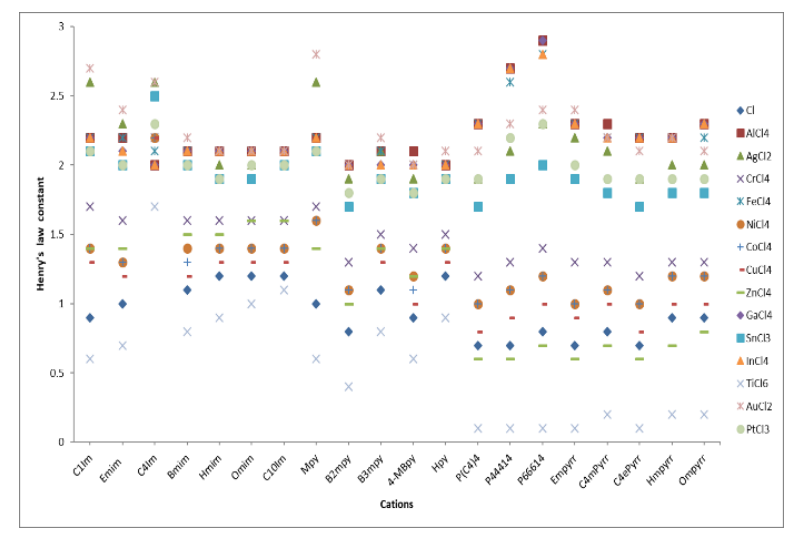

Fig. 1. Henry's law constants of $\mathrm{H}_{2} \mathrm{~S}$ in $300 \mathrm{ILs}$ at $\mathrm{T}=298.15 \mathrm{~K}$ and $\mathrm{P}=101.325 \mathrm{kPa}$.

\subsection{Activity coefficient}

The activity coefficient $(\gamma)$ of $\mathrm{H}_{2} \mathrm{~S}$ at infinite dilution in $300 \mathrm{ILs}$ at $298.15 \mathrm{~K}$ is calculated from the COSMO-RS prediction results and is displayed in Figure 2 below. The activity coefficient values exhibit the same trends as Henry's law constant values which means the effect of anions and cations are important in designing new ionic liquids.

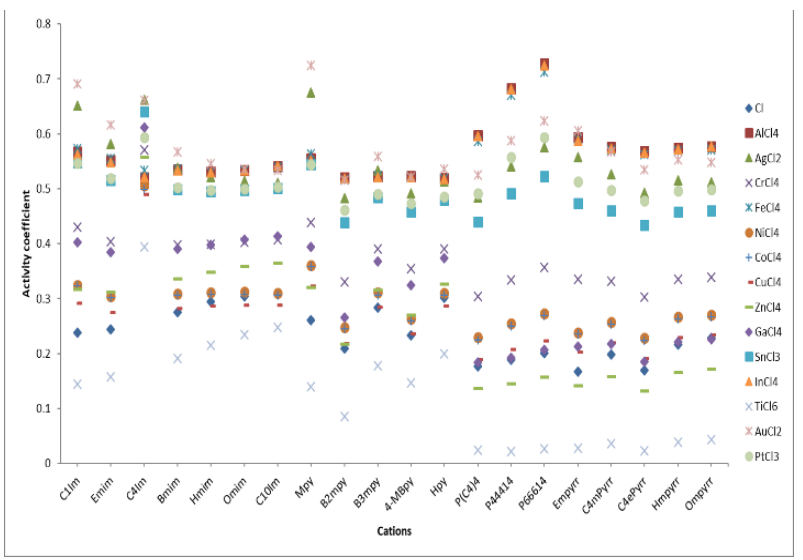

Fig. 2. The activity coefficient $(\gamma)$ of $\mathrm{H}_{2} \mathrm{~S}$ at infinite dilution in $300 \mathrm{ILs}$ at $\mathrm{T}=298.15 \mathrm{~K}$ and $\mathrm{P}=101.325 \mathrm{kPa}$.

Based on the comparison of $\gamma^{\infty}$ values, there is no specific trend observable regarding the change of cations and anions in the metal chloride anion based ILs. Further calculations of selectivity, capacity and performance index were performed at $298.15 \mathrm{~K}$ and $1 \mathrm{~atm}$ pressure to screen the most promising metal chloride anion based ILs for direct conversion of $\mathrm{H}_{2} \mathrm{~S}$ [44].

\subsection{Selectivity}

The selectivity for $\mathrm{H}_{2} \mathrm{~S}$ in 300 different ILs from a combination of 20 cations and 15 anions were predicted via COSMO-RS method. The selectivity for $\mathrm{H}_{2} \mathrm{~S}$ over $\mathrm{O}_{2}$ in $300 \mathrm{ILs}$ at $298.15 \mathrm{~K}$ predicted by COSMO-RS is shown in a graph presented in Figure 3. 


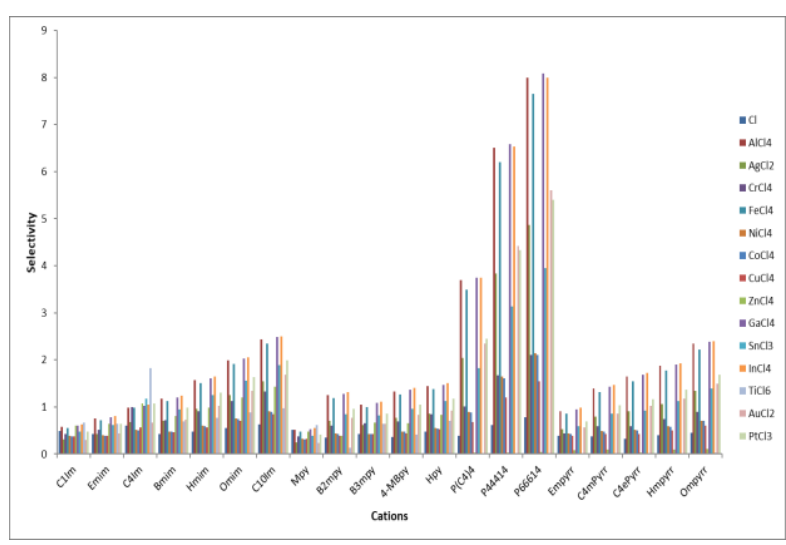

Fig. 3. Selectivity at infinite dilution for $\mathrm{H}_{2} \mathrm{~S}$ over $\mathrm{O}_{2}$ in $300 \mathrm{ILs}$ at $\mathrm{T}=298.15 \mathrm{~K}$ and $\mathrm{P}=101.325 \mathrm{kPa}$.

Based on the comparison of cations, the selectivity for $\mathrm{H}_{2} \mathrm{~S}$ at infinite dilution increases in the following order. Pyridinium $<$ imidazolium $<$ pyrrolidinium $<$ phosphonium. Phosphonium-based ILs cations such as $\left[\mathrm{P}\left(\mathrm{C}_{4}\right)_{4}\right],\left[\mathrm{P}_{44414}\right]$ and $\left[\mathrm{P}_{66614}\right]$ displayed a high selectivity compared to the rest of cations. The interactions between cations are mainly due to hydrogen bonding between the cation and the polyaromatic molecule heteroatom and with the polyaromatic compounds $\pi$-electron cloud [45].

It is observable that cations that do not possess aromatic rings such as phosphonium-based and pyrrolidinium-based ILs have higher selectivity than the cations having aromatic rings such as imidazolium-based and pyridinium-based ILs. This occurs because of the stearic hindrance of cations towards hetero-atomic polyaromatic compounds [46] that encourage the delocalization of charge in cations possessing an aromatic ring. The stearic hindrance reduces the hydrogen bonding strength between cation and heteroatoms of polyaromatic molecules hence, resulting in lower selectivity.

Meanwhile, in cations without aromatic rings, the charge delocalization in the ring does not exist due to the absence of $\pi$-electron cloud resulting in better interaction with polyaromatic molecules [47]. In addition, as the number of heteroatoms increases in the cation, the sharing of charges also increases which could lead to higher ability of the cations to interact. The interaction between heteroatomic molecules in ILs is because of the Coulombic interaction and highly dependent on the electronegative strength and number of anions. This interaction eventually leads to the formation of hydrogen bonding with heteroatomic polyaromatic molecule. Hence, based on the infinite dilution selectivity order of $\mathrm{H}_{2} \mathrm{~S}$ of cations, phosphonium-based ILs such as $\left[\mathrm{P}\left(\mathrm{C}_{4}\right)_{4}\right],\left[\mathrm{P}_{44414}\right]$ and $\left[\mathrm{P}_{66614}\right]$ are recommended as the favorable cations.

Based on the comparison of anions, it was clearly evident that the selectivity for $\mathrm{H}_{2} \mathrm{~S}$ is found to be related with the electronegativity of anions. Higher oxidation state elements are more electronegative as they are more capable to attract and stabilize the electrons. The order of selectivity for $\mathrm{H}_{2} \mathrm{~S}$ at infinite dilution of anions irrespective of cations increases in the following order. $\left[\mathrm{TiCl}_{6}\right]^{2-}<\left[\mathrm{ZnCl}_{4}\right]^{2-}<[\mathrm{Cl}]^{-}<\left[\mathrm{CuCl}_{4}\right]^{2-}<\left[\mathrm{CoCl}_{4}\right]^{2-}<$ $\left[\mathrm{NiCl}_{4}\right]^{2-}<\left[\mathrm{CrCl}_{4}\right]^{-}<\left[\mathrm{SnCl}_{3}\right]^{-}<\left[\mathrm{AgCl}_{2}\right]^{-}<\left[\mathrm{PtCl}_{3}\right]^{-}<$ $\left[\mathrm{AuCl}_{2}\right]^{-}<\left[\mathrm{FeCl}_{4}\right]^{-}<\left[\mathrm{AlCl}_{4}\right]^{-}<\left[\mathrm{InCl}_{4}\right]^{-}<\left[\mathrm{GaCl}_{4}\right]^{-}$.
Selectivity of $\mathrm{H}_{2} \mathrm{~S}$ is found to be directly related with the electronegativity of the anions. Higher oxidation state elements are more electronegative as they are more capable to attract and stabilize the electrons. Selectivity for $\mathrm{H}_{2} \mathrm{~S}$ increases as the oxidation states of the metal used in metal chloride anions increases. The greater electronegativity of the anions leads to the increase in the selectivity of $\mathrm{H}_{2} \mathrm{~S}$ [48]. Higher electronegativity of the anions such as $\mathrm{GaCl}_{4}, \mathrm{InCl}_{4}, \mathrm{AlCl}_{4}$ and $\mathrm{FeCl}_{4}$ led to higher selectivity as compared to the other metal chloride anions [49]. Hence, based on the selectivity at infinite dilution order of $\mathrm{H}_{2} \mathrm{~S}$ of anions, anion of tetrachlorogallate, $\left[\mathrm{GaCl}_{4}\right]$ is recommended as the most favorable anion.

\subsection{Capacity}

The capacity for $\mathrm{H}_{2} \mathrm{~S}$ in 300 different ILs from a combination of 20 cations and 15 anions were predicted via COSMO-RS method. The capacity for $\mathrm{H}_{2} \mathrm{~S}$ over $\mathrm{O}_{2}$ in $300 \mathrm{ILs}$ at $298.15 \mathrm{~K}$ predicted by COSMO-RS is shown in a graph presented in Figure 4.

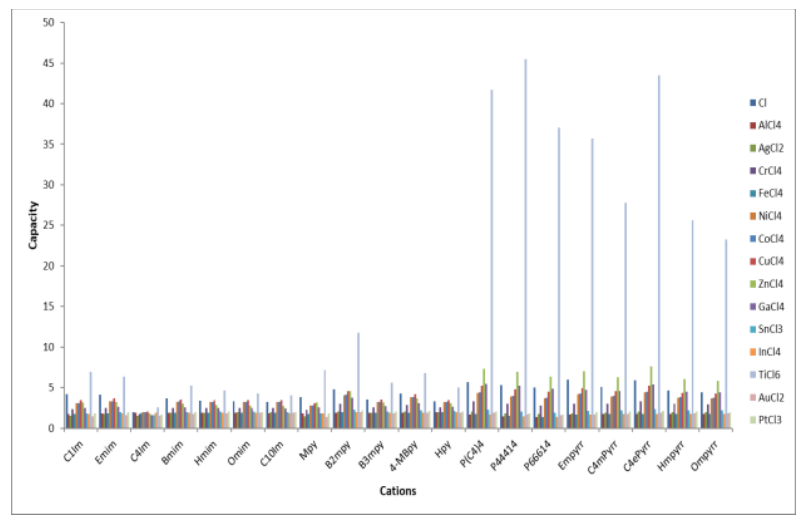

Fig. 4. Capacity at infinite dilution of $\mathrm{H}_{2} \mathrm{~S}$ in 300 ILs at $\mathrm{T}=298.15 \mathrm{~K}$ and $\mathrm{P}=101.325 \mathrm{kPa}$.

In general, the capacity of metal chloride anion based ILs does not provide any reasonable trend. The order of capacity for $\mathrm{H}_{2} \mathrm{~S}$ in metal chloride anion based ILs based on group of cations irrespective of anions increases in the following order. Imidazolium $<$ pyridinium $<$ pyrrolidinium $<$ phosphonium. By comparing the cations, the results indicated that the capacity increases as the $\pi$ electron cloud of cations decreases [44]. The cations without aromatic rings such as phosphonium-based and pyrrolidinium-based ILs possess a higher capacity compared to the cations having aromatic rings such as pyridinium-based and imidazolium-based ILs. This happens due to the presence of delocalized electrons in the cations with aromatic ring causes a strong stearic hindrance towards the hetero-atomic polyaromatic compounds [46]. As a result, they possess a lower capacity for $\mathrm{H}_{2} \mathrm{~S}$ molecules.

Due to the absence of $\pi$-electron cloud in nonaromatic cations, there is no charge delocalization in the ring and results in more effective interaction with $\mathrm{H}_{2} \mathrm{~S}$ molecules. In addition, as the number of heteroatoms increases in the cation, the sharing of charges also increases which could lead to higher ability of the cations 
to interact [47]. This interaction eventually leads to the formation of hydrogen bonding with hetero-atomic polyaromatic molecule. Hence, based on the comparison of $\mathrm{H}_{2} \mathrm{~S}$ capacity in the cations, phosphonium-based ILs were selected as the favorable cations since they possess a higher capacity compared to the rest of cations.

Based on the comparisons of anions irrespective of cations, it can be seen that the hexachlorotitanate anion, $\left[\mathrm{TiCl}_{6}\right]^{2-}$ based ILs demonstrated a very high capacity for $\mathrm{H}_{2} \mathrm{~S}$ absorption compared to the rest of the anions. The trend is similar with the prediction trend of $\mathrm{H}_{2} \mathrm{~S}$ solubility in metal chloride anion based ILs discussed earlier. This is probably because titanium metal in hexachlorotitanate anion [50] is the least electronegative compared to the rest of metals used in metal chloride anion based ILs. Its low electronegativity contributed to its high capacity for $\mathrm{H}_{2} \mathrm{~S}$ molecules.

However, hexachlorotitanate anion, $\left[\mathrm{TiCl}_{6}\right]^{2-}$ based ILs are not suitable anions for selection as they possess a very low selectivity towards $\mathrm{H}_{2} \mathrm{~S}$ even though they have a very high capacity for $\mathrm{H}_{2} \mathrm{~S}$ molecules. In general, the solvents which possess high capacity tends to have a very low selectivity for the solute molecules [51]. Thus, it is not economically viable to choose a solvent which requires only a small volume but has a very poor interaction to yield the main product which is elemental sulfur, $\mathrm{S}_{8}$ in this particular study. Therefore, it is necessary to consider the solvents which possess a reasonable magnitude in both selectivity and capacity for selection.

\subsection{Performance Index}

The performance index (PI) values for a total of 300 ILs from a combination of 20 cations and 15 anions are presented in a graph of performance index in 300 ILs at 298.15 K as in Figure 5. The PI values are calculated using equation (3) via COSMO-RS model.

Generally, the solvents which possess a high capacity tend to have a low selectivity to yield the products instead and vice versa. Hence, it is not economically viable to choose a solvent which require a small volume but has a poor interaction instead. Thus, it is crucial to identify a solvent which possess both properties in a reasonable magnitude.

By comparing the performances of cations in 300 ILs, it is obvious that phosphonium-based ILs such as $\left[\mathrm{P}\left(\mathrm{C}_{4}\right)_{4}\right],\left[\mathrm{P}_{44414}\right]$ and $\left[\mathrm{P}_{66614}\right]$ have higher PI values due to higher selectivity and capacity values respectively. This also indicated that phosphonium-based ILs might give better results in real conversion of $\mathrm{H}_{2} \mathrm{~S}$ experiment compared to the pyrrolidinium-based, imidazolium-based and pyridinium based ILs.

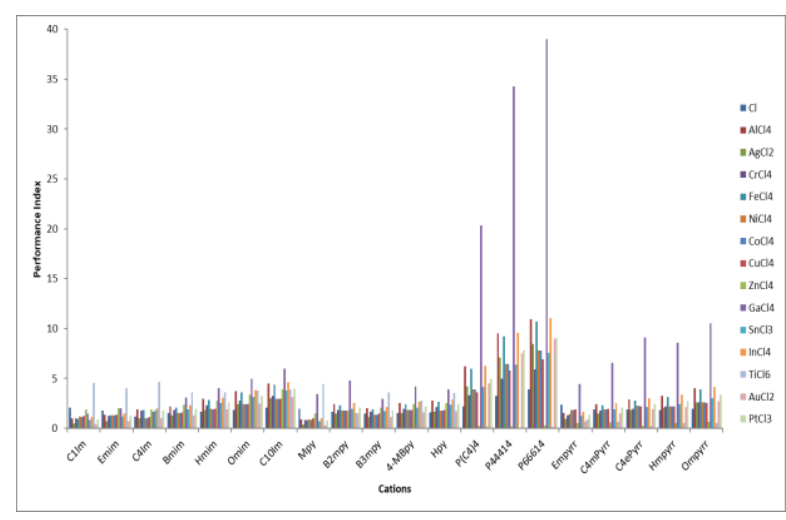

Fig. 5. Performance index for $\mathrm{H}_{2} \mathrm{~S}$ in $300 \mathrm{ILs}$ at $\mathrm{T}=298.15 \mathrm{~K}$ and $\mathrm{P}=101.325 \mathrm{kPa}$.

By comparing the performances of anions in $300 \mathrm{ILs}$, it is obvious that certain metal chloride anion-based ILs have higher PI values such as tetrachlorogallate anion, $\left[\mathrm{GaCl}_{4}\right]^{-}$, tetrachloroindium anion, $\left[\mathrm{InCl}_{4}\right]^{-}$, tetrachloroaluminate anion, $\left[\mathrm{AlCl}_{4}\right]^{-}$and tetrachloroferrate anion, $\left[\mathrm{FeCl}_{4}\right]^{-}$based ILs due to their higher selectivity and capacity values respectively. However, metal chloride anion-based ILs such as hexachlorotitanate anion-based ILs, $\left[\mathrm{TiCl}_{6}\right]^{2-}$ displayed low PI value as it possesses a very high capacity, but has a very low selectivity instead.

Therefore, it can be concluded that ILs with higher values of capacity and selectivity will possess a higher performance index. These ILs are also predicted to be more efficient in performing $\mathrm{H}_{2} \mathrm{~S}$ conversion and thus, favorable to be selected for synthesis.

\subsection{Selection of metal chloride anion based ILs for synthesis}

Based on the performance index, PI predicted by COSMORS on 300 ILs' performance in $\mathrm{H}_{2} \mathrm{~S}$ conversion, trihexyltetradecylphosphonium ion, $\left[\mathrm{P}_{66614}\right]^{+}$and tetrabutyltetradecylphosphonium ion, $\left[\mathrm{P}_{44414}\right]^{+}$were the two best cations of ILs after being compared with every anion in the screening process. However, recent findings revealed that ILs containing $\left[\mathrm{P}_{44414}\right]^{+}$are extremely toxic and carcinogenic to human beings. Hence, its production is no longer continued worldwide. Therefore, only trihexyltetradecylphosphonium cation, $\left[\mathrm{P}_{66614}\right]^{+}$is chosen for synthesis.

Meanwhile, tetrachlorogallate ion, $\left[\mathrm{GaCl}_{4}\right]^{-}$is predicted as the best anion with the highest peformance for $\mathrm{H}_{2} \mathrm{~S}$ conversion when paired with every cation during the screening process followed by tetrachloroindium ion, $\left[\mathrm{InCl}_{4}\right]^{-}$, tetrachloroaluminate ion, $\left[\mathrm{AlCl}_{4}\right]^{-}$and tetrachloroferrate ion, $\left[\mathrm{FeCl}_{4}\right]^{-}$. In the economic value aspects, iron(III) chloride, $\mathrm{FeCl}_{3}$ and tin(II) chloride, $\mathrm{SnCl}_{2}$ are lower in cost compared to the rest of metal chlorides.

Therefore, by considering various aspects of ILs selection such as $\mathrm{H}_{2} \mathrm{~S}$ conversion performance, safety reasons and economic value, 3 ILs has been selected for synthesis such as trihexyl(tetradecyl)phosphonium tetrachlorogallate, $\quad\left[\mathrm{P}_{66614}\right]\left[\mathrm{GaCl}_{4}\right]$, trihexyl(tetradecyl)phosphonium tetrachloroferrate, $\left[\mathrm{P}_{66614}\right]\left[\mathrm{FeCl}_{4}\right]$ and trihexyl(tetradecyl)phosphonium trichlorostannate, $\left[\mathrm{P}_{66614}\right]\left[\mathrm{SnCl}_{3}\right]$. 


\section{Conclusion}

Task-Specific Ionic Liquids such as metal chloride anion based ILs have a high potential to be developed as reaction media for the conversion of $\mathrm{H}_{2} \mathrm{~S}$. By considering high conversion efficiency can be achieved by these TSILs, they are also expected to promote a faster conversion of $\mathrm{H}_{2} \mathrm{~S}$ into $\mathrm{S}_{8}$.

However, the process of selecting and identifying the best possible metal chloride anion based ILs is very tedious, time consuming and expensive if it is carried out experimentally. Therefore, an efficient screening method with high accuracy is required. In order to identify the best possible reaction media for performing $\mathrm{H}_{2} \mathrm{~S}$ conversion, a total number of 300 different ILs from a combination of 20 cations and 15 anions were screened via COSMO-RS model simulations.

By COSMO-RS method, thermodynamic and physicochemical properties of 300 ILs such as Henry's law constants, activity coefficient, selectivity, capacity and performance index are obtained and analyzed. Thus, by comparing the performance of ILs via COSMO-RS, a series of TSILs containing cation of $\left[\mathrm{P}_{66614}\right]$ with metal chloride anions such as $\mathrm{Ga}, \mathrm{Fe}$ and $\mathrm{Sn}$ were selected based on their performance predicted by COSMO-RS, economic and safety values.

Consequently, the physicochemical properties such as density, viscosity, thermal properties, as well as $\mathrm{H}_{2} \mathrm{~S}$ oxidation performances in those TSILs will be systematically investigated.

The authors gratefully acknowledge the Yayasan Universiti Teknologi PETRONAS (YUTP) for funding the research work under the YUTP-Fundamental Research Grant Scheme (YUTPFRG 015LC0-263), Universiti Teknologi PETRONAS (UTP), the research officers and postgraduate students for their assistance in each aspect of research.

\section{References}

[1] E. Total, "Sour Gas, A History of Expertise," Group, vol. 24, (2007).

[2] A. J. Kidnay, W. R. Parrish, and D. G. McCartney, Fundamentals of natural gas processing. CRC press, 2019.

[3] P. C. Database. "Hydrogen sulfide." National Center for Biotechnology Information (2020). https://pubchem.ncbi.nlm.nih.gov/compound/Hydrogensulfide (accessed September 4, 2020).

[4] O. S. a. H. Administration. "Safety and Health Topics / Hydrogen Sulfide " Occupational Safety and Health Administration.

https://www.osha.gov/SLTC/hydrogensulfide/hazards.html (accessed September 4, 2020).

[5] M. J. Goodwin, O. M. Musa, and J. W. Steed, "Problems associated with sour gas in the oilfield industry and their solutions," Energy \& Fuels, vol. 29, no. 8, pp. 4667-4682, (2015).

[6] M. Abdul Aziz and A. Mithani, "Holistic Approach in Managing Challenges of Mature Offshore Carbonate Gas Fields with High CO 2 and H 2 S Content in Sarawak Gas Operations, MALAYSIA," in SPE Oil and Gas India Conference and Exhibition, (2017): Society of Petroleum Engineers.

[7] K. Huang, X. Feng, X.-M. Zhang, Y.-T. Wu, and X.-B. Hu, "The ionic liquid-mediated Claus reaction: a highly efficient capture and conversion of hydrogen sulfide," Green Chemistry, vol. 18, no. 7, pp. 1859-1863, (2016).

[8] P. K. Mohapatra, "Actinide ion extraction using room temperature ionic liquids: opportunities and challenges for nuclear fuel cycle applications," Dalton Transactions, vol. 46, no. 6, pp. 1730-1747, (2017).

[9] D. Shang et al., "Ionic liquids in gas separation processing," Current Opinion in Green and Sustainable Chemistry, vol. 5, pp. 74-81, (2017).

[10] J.-G. Lu, Y.-F. Zheng, and D.-L. He, "Selective absorption of $\mathrm{H} 2 \mathrm{~S}$ from gas mixtures into aqueous solutions of blended amines of methyldiethanolamine and 2-tertiarybutylamino2-ethoxyethanol in a packed column," Separation and purification technology, vol. 52, no. 2, pp. 209-217, (2006).

[11] X. Zhao, H. Xing, R. Li, Q. Yang, B. Su, and Q. Ren, "Gas separation based on ionic liquids," Progress in Chemistry, vol. 23, no. 11, p. 2258, (2011).

[12] Z. Guo et al., "Nonaqueous system of iron-based ionic liquid and DMF for the oxidation of hydrogen sulfide and regeneration by electrolysis," Environmental science \& technology, vol. 49, no. 9, pp. 5697-5703, (2015).

[13] J. Wang and W. Zhang, "Oxidative absorption of hydrogen sulfide by iron-containing ionic liquids," Energy \& fuels, vol. 28, no. 9, pp. 5930-5935, (2014).

[14] O. Brettschneider, R. Thiele, R. Faber, H. Thielert, and G. Wozny, "Experimental investigation and simulation of the chemical absorption in a packed column for the system NH3CO2-H2S-NaOH-H2O," Separation and Purification Technology, vol. 39, no. 3, pp. 139-159, (2004).

[15] Y. Zhao, J. Gao, Y. Huang, R. M. Afzal, X. Zhang, and S. Zhang, "Predicting H 2 S solubility in ionic liquids by the quantitative structure-property relationship method using $\mathrm{S}$ $\sigma$-profile molecular descriptors," RSC advances, vol. 6, no. 74, pp. 70405-70413, (2016).

[16] H. Sakhaeinia, A. H. Jalili, V. Taghikhani, and A. A. Safekordi, "Solubility of H2S in Ionic Liquids 1-Ethyl-3methylimidazolium Hexafluorophosphate ([emim][PF6]) and 1-Ethyl-3-methylimidazolium Bis (trifluoromethyl) sulfonylimide ([emim][Tf2N])," Journal of Chemical \& Engineering Data, vol. 55, no. 12, pp. 5839-5845, (2010).

[17] C. Chiappe and C. S. Pomelli, "Hydrogen sulfide and ionic liquids: absorption, separation, and oxidation," in Ionic Liquids II: Springer, (2017), pp. 265-289.

[18] C. Wang, Y. Guo, X. Zhu, G. Cui, H. Li, and S. Dai, "Highly efficient $\mathrm{CO} 2$ capture by tunable alkanolamine-based ionic liquids with multidentate cation coordination," Chemical Communications, vol. 48, no. 52, pp. 6526-6528, (2012).

[19] F. Ding et al., "Highly efficient and reversible SO2 capture by surfactant-derived dual functionalized ionic liquids with metal chelate cations," Industrial \& Engineering Chemistry Research, vol. 53, no. 48, pp. 18568-18574, (2014).

[20] B. Guo, E. Duan, Y. Zhong, L. Gao, X. Zhang, and D. Zhao, "Absorption and oxidation of H2S in caprolactam tetrabutyl ammonium bromide ionic liquid," Energy \& fuels, vol. 25, no. 1, pp. 159-161, (2011).

[21] M. Tariq, P. Forte, M. C. Gomes, J. C. Lopes, and L. Rebelo, "Densities and refractive indices of imidazolium-and phosphonium-based ionic liquids: Effect of temperature, alkyl chain length, and anion," The Journal of Chemical Thermodynamics, vol. 41, no. 6, pp. 790-798, (2009).

[22] T. Koishi, "Molecular dynamics study of the effect of water on hydrophilic and hydrophobic ionic liquids," The Journal of Physical Chemistry B, vol. 122, no. 51, pp. 12342-12350, (2018).

[23] L. F. Vega, O. Vilaseca, F. Llovell, and J. S. Andreu, "Modeling ionic liquids and the solubility of gases in them: recent advances and perspectives," Fluid Phase Equilibria, vol. 294, no. 1-2, pp. 15-30, (2010).

[24] A. A. Freitas, K. Shimizu, and J. N. Canongia Lopes, "Complex structure of ionic liquids. Molecular Dynamics studies with different cation-anion combinations," Journal of Chemical \& Engineering Data, vol. 59, no. 10, pp. 31203129, (2014).

[25] A. Klamt, F. Eckert, and W. Arlt, "COSMO-RS: an alternative to simulation for calculating thermodynamic properties of liquid mixtures," Annual review of chemical and biomolecular engineering, vol. 1, pp. 101-122, (2010). 
[26] S. Gao, X. Chen, R. Abro, A. A. Abdeltawab, S. S. Al-Deyab, and G. Yu, "Desulfurization of fuel oil: conductor-like screening model for real solvents study on capacity of ionic liquids for thiophene and dibenzothiophene," Industrial \& Engineering Chemistry Research, vol. 54, no. 38, pp. 94219430, (2015).

[27] N. R. Varma, A. Ramalingam, and T. Banerjee, "Experiments, correlations and COSMO-RS predictions for the extraction of benzothiophene from n-hexane using imidazolium-based ionic liquids," Chemical engineering journal, vol. 166, no. 1, pp. 30-39, (2011).

[28] R. Anantharaj and T. Banerjee, "COSMO-RS based predictions for the desulphurization of diesel oil using ionic liquids: Effect of cation and anion combination," Fuel processing technology, vol. 92, no. 1, pp. 39-52, (2011).

[29] A. R. Ferreira, M. G. Freire, J. C. Ribeiro, F. M. Lopes, J. G. Crespo, and J. A. Coutinho, "Ionic liquids for thiols desulfurization: experimental liquid-liquid equilibrium and COSMO-RS description," Fuel, vol. 128, pp. 314-329, (2014).

[30] Z. Song, T. Zhou, J. Zhang, H. Cheng, L. Chen, and Z. Qi, "Screening of ionic liquids for solvent-sensitive extractionwith deep desulfurization as an example," Chemical Engineering Science, vol. 129, pp. 69-77, (2015).

[31] M. Diedenhofen, F. Eckert, and A. Klamt, "Prediction of infinite dilution activity coefficients of organic compounds in ionic liquids using COSMO-RS," Journal of Chemical \& Engineering Data, vol. 48, no. 3, pp. 475-479, (2003).

[32] C. Steffen, K. Thomas, U. Huniar, A. Hellweg, O. Rubner, and A. Schroer, "TmoleX - a graphical user interface for TURBOMOLE," Journal of computational chemistry, vol. 31, no. 16, pp. 2967-2970, (2010).

[33] A. Klamt, "The COSMO and COSMO-RS solvation models," Wiley Interdisciplinary Reviews: Computational Molecular Science, vol. 1, no. 5, pp. 699-709, (2011).

[34] A. Klamt, V. Jonas, T. Bürger, and J. C. Lohrenz, "Refinement and parametrization of COSMO-RS," The Journal of Physical Chemistry A, vol. 102, no. 26, pp. 50745085, (1998).

[35] F. Eckert and A. Klamt, "COSMOthermX version C30_1701; COSMOlogic GmbH \& Co," KG, Leverkusen, Germany, (2016).

[36] J. M. Parnis, D. Mackay, and T. Harner, "Temperature dependence of Henry's law constants and KOA for simple and heteroatom-substituted PAHs by COSMO-RS," Atmospheric Environment, vol. 110, pp. 27-35, (2015).

[37] K. Paduszyński and M. Królikowska, "Effect of Side Chain Functional Group on Interactions in Ionic Liquid Systems: Insights from Infinite Dilution Thermodynamic Data," The Journal of Physical Chemistry B, vol. 121, no. 43, pp. 1013310145, (2017).

[38] M. Krummen, D. Gruber, and J. Gmehling, "Measurement of activity coefficients at infinite dilution in solvent mixtures using the dilutor technique," Industrial \& Engineering Chemistry Research, vol. 39, no. 6, pp. 2114-2123, (2000).

[39] M. Gonzalez-Miquel, J. Palomar, S. Omar, and F. Rodriguez, "CO2/N2 selectivity prediction in supported ionic liquid membranes (SILMs) by COSMO-RS," Industrial \& Engineering Chemistry Research, vol. 50, no. 9, pp. 57395748, (2011).

[40] X. Zhao et al., "Design and screening of ionic liquids for $\mathrm{C} 2 \mathrm{H} 2 / \mathrm{C} 2 \mathrm{H} 4$ separation by COSMO-RS and experiments," AIChE Journal, vol. 61, no. 6, pp. 2016-2027, (2015).

[41] K. Paduszyński, "An overview of the performance of the COSMO-RS approach in predicting the activity coefficients of molecular solutes in ionic liquids and derived properties at infinite dilution," Physical Chemistry Chemical Physics, vol. 19, no. 19, pp. 11835-11850, (2017).

[42] O. O. Wahab, L. O. Olasunkanmi, K. K. Govender, and P. P. Govender, "DMol3/COSMO-RS prediction of aqueous solubility and reactivity of selected Azo dyes: Effect of global orbital cut-off and COSMO segment variation," Journal of Molecular Liquids, vol. 249, pp. 346-360, (2018). K. Li and D. Xue, "Estimation of electronegativity values of elements in different valence states," The Journal of Physical Chemistry A, vol. 110, no. 39, pp. 11332-11337, (2006).
Z. Rashid, C. D. Wilfred, N. Gnanasundaram, A. Arunagiri, and T. Murugesan, "Screening of ionic liquids as green oilfield solvents for the potential removal of asphaltene from simulated oil: COSMO-RS model approach," Journal of Molecular Liquids, vol. 255, pp. 492-503, (2018).

[45] C. C. Cassol, A. P. Umpierre, G. Ebeling, B. Ferrera, S. S Chiaro, and J. Dupont, "On the extraction of aromatic compounds from hydrocarbons by imidazolium ionic liquids," International Journal of Molecular Sciences, vol. 8 , no. 7 , pp. 593-605, (2007).

[46] R. K. Bansal, Heterocyclic chemistry. New Age International, (2008).

[47] R. Anantharaj and T. Banerjee, "COSMO-RS-based screening of ionic liquids as green solvents in denitrification studies," Industrial \& engineering chemistry research, vol. 49, no. 18, pp. 8705-8725, (2010).

[48] C. Zhang et al., "Study of the toluene absorption capacity and mechanism of ionic liquids using COSMO-RS prediction and experimental verification," Green Energy \& Environment, (2020).

[49] Y.-S. Liu et al., "Ionic liquids: novel solvents for petroleum asphaltenes," Chinese Journal of Chemical Engineering, vol. 13, no. 4, pp. 564-567, (2005).

[50] R. Lister and S. Flengas, "The Synthesis and Properties of the Anhydrous Hexachlorotitanates of Rubidium and Cesium," Canadian journal of chemistry, vol. 41, no. 6, pp. 1548-1551, (1963).

[51] R. Putnam, R. Taylor, A. Klamt, F. Eckert, and M. Schiller, "Prediction of infinite dilution activity coefficients using COSMO-RS," Industrial \& engineering chemistry research, vol. 42, no. 15, pp. 3635-3641, (2003). 